\title{
SUR LA CULTURE DU TREPONEMA HISPANICUM
}

Par R. V. TALICE et N. SURRACO

La question de la culture des spirochètes de fièvres récurrentes est déjà ancienne. Depuis les premiers travaux de Levaditi et de Noguchi, la bibliographie est devenue considérable. Aujourd'hui, on sait que les spirochètes parasites du sang peuvent être cultivés en série sur différents milieux.

Dans cet article, nous ne voulons exposer que les résultats de recherches faites sur la culture du Treponema hispanicum Sadi de Buen, 1926.

La culture de ce spirochète a été obtenue pour la première fois par Aznar en 1926. Cet auteur a employé le milieu d'Ungermann et et ceux d'Aristowsky et Hœltzer. Aznar a vu des spirochètes vivant jusqu'à 28 jours dans les tubes laissés à la température de $15^{\circ}$ à $18^{\circ}$. Il a pu obtenir jusqu'à 8 repiquages. Il ne dit pas si la virulence a été conservée.

Nicolle et Anderson en 1926, dans un travail d'ensemble sur les les virus récurrents pathogènes pour l'homme, consacrent quelques lignes à la culture du $T$. hispanicum. Au total, ils ont pu conserver le virus virulent pendant 15 jours en conditions artificielles, en suivant la technique de W. Aristowsky et Hœltzer.

Lapidari et Sparrow, en 1928, sont arrivés à cultiver dans le milieu d'Ungermann plusieurs spirochètes des fièvres récurrentes, parmi lesquels le $T$. hispanicum. Les auteurs ont "réussi à entretenir des cultures plus riches en employant un bouillon digéré par le suc pancréatique, e'est-à-dire le milieu de Hartley additionné à la fois de sérum de lapin inactivé à $56-58^{\circ}$, de sang frais et d'albumine d'œuf coagulée. Les cultures sur ce milieu ont, en outre, conservé plus longtemps leur vitalité et leur virulence. 》 Les repiquages réussissent facilement quand la première culture est faite avec du sang d'un animal contenant de très nombreux spirochètes.

Expériences personnelles. - Nous nous sommes servi, dans les premiers essais, du milieu d’Ungermann qui a été considéré par presque tous les auteurs, comme celui qui donne les résultats les plus sûrs. Ce milieu est composé de sérum de lapin au cinquième dans la solution de Ringer. On répartit dans des tubes en verre vert

Anvales de Parasitologie, $T$. VII, $\mathrm{x}^{\circ} 2 .-1^{\text {er }}$ mars 1929 , p. 133-139. 
longs et étroits ( 1 cent. de diamètre sur 12 de longueur). On inactive au bain-marie à $56^{\circ}$ pendant 30 minutes, on recouvre d'une couche d'un centimètre et demi d'huile de vaseline stérile et on conserve à la glacière. Avant de s'en servir, on ajoute dans chaque tube 3 gouttes de sang frais de lapin.

Pour nos premiers ensemencements, nous nous sommes toujours servi de sang de rat ou de cobaye, prélevé par ponction aseptique du cœur et présentant d'abondants spirochètes à l'ultra-microscope. Les tubes ont été conservés à $37^{\circ}$. L'examen des cultures a été fait tous les jours sur des préparations à l'état frais, à l'ultramicroscope et en utilisant toujours le même grossissement.

Les premiers résultats ont été, comme souvent, très irréguliers. On sait en effet « que les spirochètes de la même espèce ensemencés sur le même milieu et dans les mêmes conditions, donnent parfois une culture qui, après un développement très abondant, ne peut être continué dans les repiquages. Il s'agit évidemment ici de l'action d'agents que nous ne connaissons pas encore ». (Lapidari et Sparrow).

Sur ce milieu, nous avons observé dans les premiers jours l'apparition de formes courtes, quelquefois avec 3 spires seulement. En même temps, on observe des formes longues en division transversale, présentant différents aspects. A cette période, on peut voir ces formes longues accolées entre elles, glissant l'une sur l'autre avec toute l'apparence des formes provenant de divisions longitudinales. Les formes les plus longues ont montré jusqu'à 30 tours de spire. Au quatrième jour, on n'observe, en général, que des formes moyennes ayant 6 à 8 tours de spire. Dès les premiers jours et pendant toute l'évolution des cultures, on peut observer quelques formes très fines, soit courtes, soit longues, mais différentes de celles presque exclusivement longues et très nombreuses qui apparaissent dans la période finale des cultures âgées. La présence de ces formes fines, souvent accolées deux à deux, indique une évolution défavorable des cultures. Au contraire, l'apparition des formes longues en division et de formes anguleuses est d'un bon pronostic.

En général, la longévité des cultures nous semble en proportion inverse de sa richesse. En effet, dans des tubes qui montraient une richesse moyenne, les spirochètes vivaient jusqu'à 16 jours, tandis que dans les tubes très riches les spirochètes mouraient après 6 ou 7 jours et les cultures s'arrêtaient brusquement et à l'improviste.

Après les premières tentatives, nous avons réussi à entretenir facilement les cultures par repiquages tous les 3 ou 4 jours. Le $3^{\circ}$ ou le $4^{\circ}$ jour est précisément le moment du maximum de développement des cultures. 
Le milieu d'Illert ne nous a pas donné des résultats aussi constants que celui d'Ungermann. Pour cette raison, nous l'avons abandonné.

La culture des spirochètes des fièvres récurrentes est basée sur quelques principes qu'on peut résumer de la façon suivante :

$1^{\circ}$ Emploi de milieux faits avec des albumines non dénaturées du sérum inactivé frais, de préférence de lapin.

$2^{\circ}$ Présence, dans ces milieux, de sang et de morceaux d'organes frais ou de tissus embryonnaires.

$3^{\circ}$ Une certaine concentration du milieu en ions hydrogène, à laquelle on attribue quelque importance dans la culture des microorganismes en général et des protozoaires en particulier.

$4^{\circ}$ Anaérobiose obtenue dans les tubes longs et étroits au moyen d'une couche d'huile de vaseline qui recouvre la surface du milieu. Au cours de nos recherches sur la culture du T. hispanicum, nous avons analysé chacun de ces principes et déterminé son influence sur la richesse et la longévité des cultures. Voici les résultats de nos observations :

$1^{\circ}$ Le sérum de lapin nous a donné de très bons résultats. Cependant, il y a toujours certains animaux dont le sérum est beaucoup plus favorable sans qu'on puisse en savoir la raison exacte.

Des expériences comparatives que nous avons faites, il résulte que l'inactivation du sérum n'a aucune influence sur la marche des cultures. Elle est absolument inutile, comme l'ont démontré Kliger et Robertson, pour le $T$. recurrentis. L'addition de parties égales de liquide de Ringer n'est pas non plus nécessaire et ne donne aucun avantage.

$2^{\circ}$ Ensuite nous avons étudié l'influence du sang frais sur la richesse et la longévité des cultures. Dans ce but, nous avons fait des cultures comparatives en tubes de sérum de lapin additionné ou non de sang frais. Cés recherches nous ont montré que l'addition de sang ne présente aucun avantage, car les tubes qui en contenaient ne montraient ni une plus grande richesse ni une plus forte longévité des spirochètes. Nous ne croyons donc pas que la fibrine du sang exerce une action stabilisante, en empêchant la libération de l'acide carbonique (Kliger et Robertson).

$3^{\circ}$ Nous ne nions pas le rôle du facteur $p \mathrm{H}$ sur les cultures de ces délicats protozoaires, mais, au point de vue pratique, la titration des milieux de cultures n'est pas nécessaire. Les observations faites au début de nos recherches ne nous ont pas démontré une relation évidente entre le $p \mathrm{H}$ du milieu et la longévité des cultures.

$4^{\circ}$ L'anaérobiose est une condition indispensable, comme on l'a démontré depuis longtemps. 
Donc, finalement, nous sommes arrivés à entretenir facilement nos cultures en repiquant les spirochètes sur un milieu d'Ungermann très simplifié, c'est-à-dire : sérum pur de lapin en anaérobiose, sans inactiver et sans globules rouges.

Le premier tube de la première souche a été ensemencé avec quelques gouttes de sang du cœur d'un rat fortement infecté, le 31 janvier 1928. En faisant des repiquages tous les 3 ou 4 jours (au total 43 passages), on a gardé les spirochètes en condition artificielle pendant 160 jours. Au mois d'août, la souche a été abandonnée volontairement. La virulence des cultures, comme nous le verrons plus loin, a été parfaitement conservée.

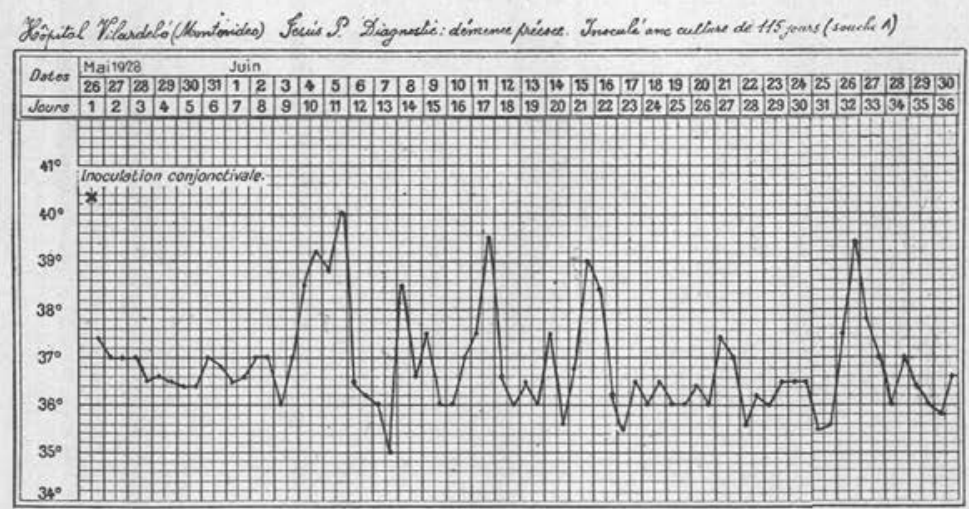

Au mois d'octobre, on a commencé à cultiver une deuxième souche, en employant dès les premiers tubes le milieu simplifié et avec la même technique. Jusqu'à la fin de l'année 1928, les spirochètes vivaient parfaitement in vitro. La virulence des cultures est conservée.

Virulence des spirochètes de cultures. - Toutes nos cultures, depuis le 31 janvier jusqu'au $1^{\text {er }}$ décembre 1928 , ont montré constamment une parfaite conservation de la virulence des spirochètes, soit pour les animaux, soit pour l'homme. On peut voir dans les tableaux et les courbes ci-joints le résultat des inoculations.

La maladie expérimentale des animaux offre les mêmes caractères que la maladie provoquée par des passages avec du sang de l'animal infecté. La période d'incubation est en général de 3 jours pour la souris, de 4 jours pour le rat. 
La maladie expérimentale, provoquée chez l'homme par les spirochètes des cultures, offre aussi les caractéristiques de la maladie qu'on obtient par inoculation du sang d'un animal infecté. L'infection a été intense, même avec les spirochètes qui vivaient in vitro depuis 155 jours; le premier accès est toujours fort (voir les
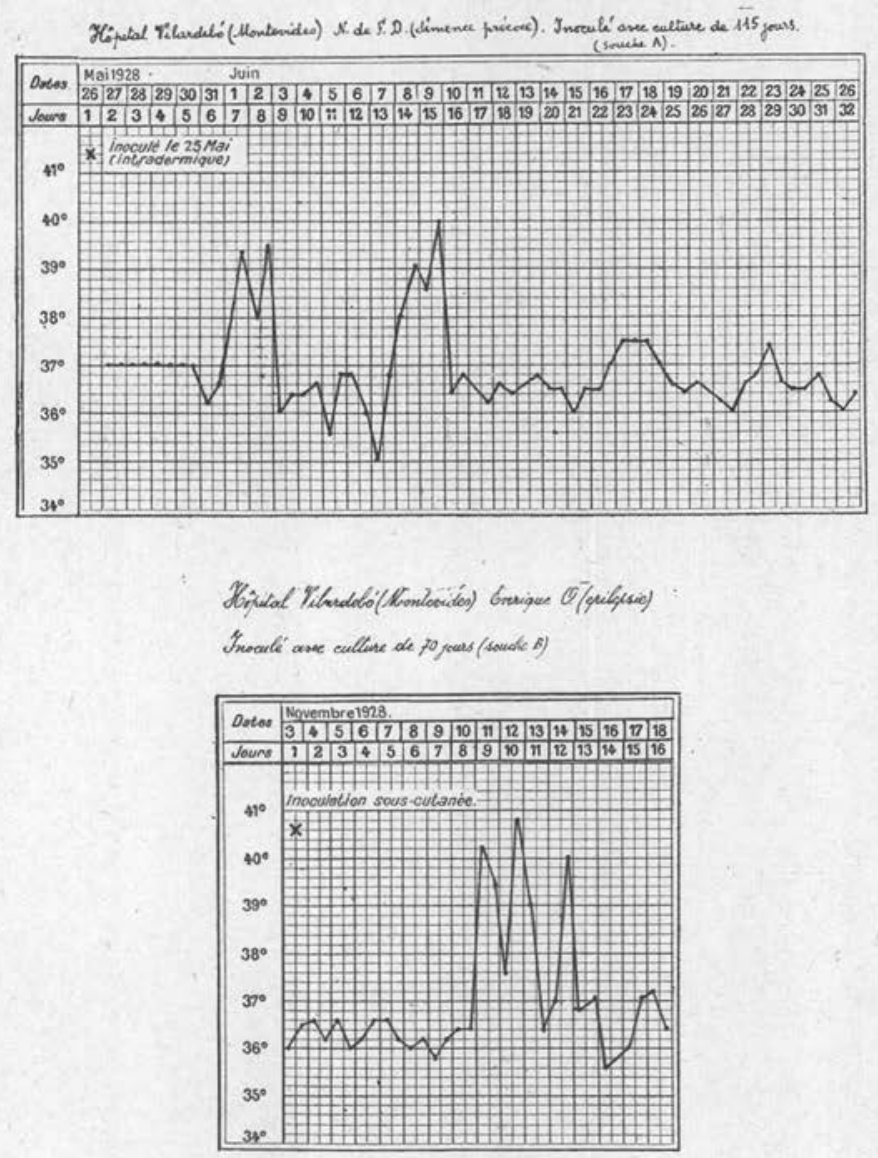

courbes ci-jointes), donc le nombre d'accès est réduit. Mais la période d'incubation, quand on inocule des cultures, est constamment plus longue que dans les cas d'inoculation de sang virulent. Nous avons observé comme chiffre extrême 7 à 11 jours, en moyenne 10 jours.

Remarquons finalement que les inoculations ont été faites par les voies intradermique, sous-cutanée et conjonctivale. 
Virulence des spirochètes de cultures. Résumé du protocole des expériences Inoculations aux animaux

Sovche A

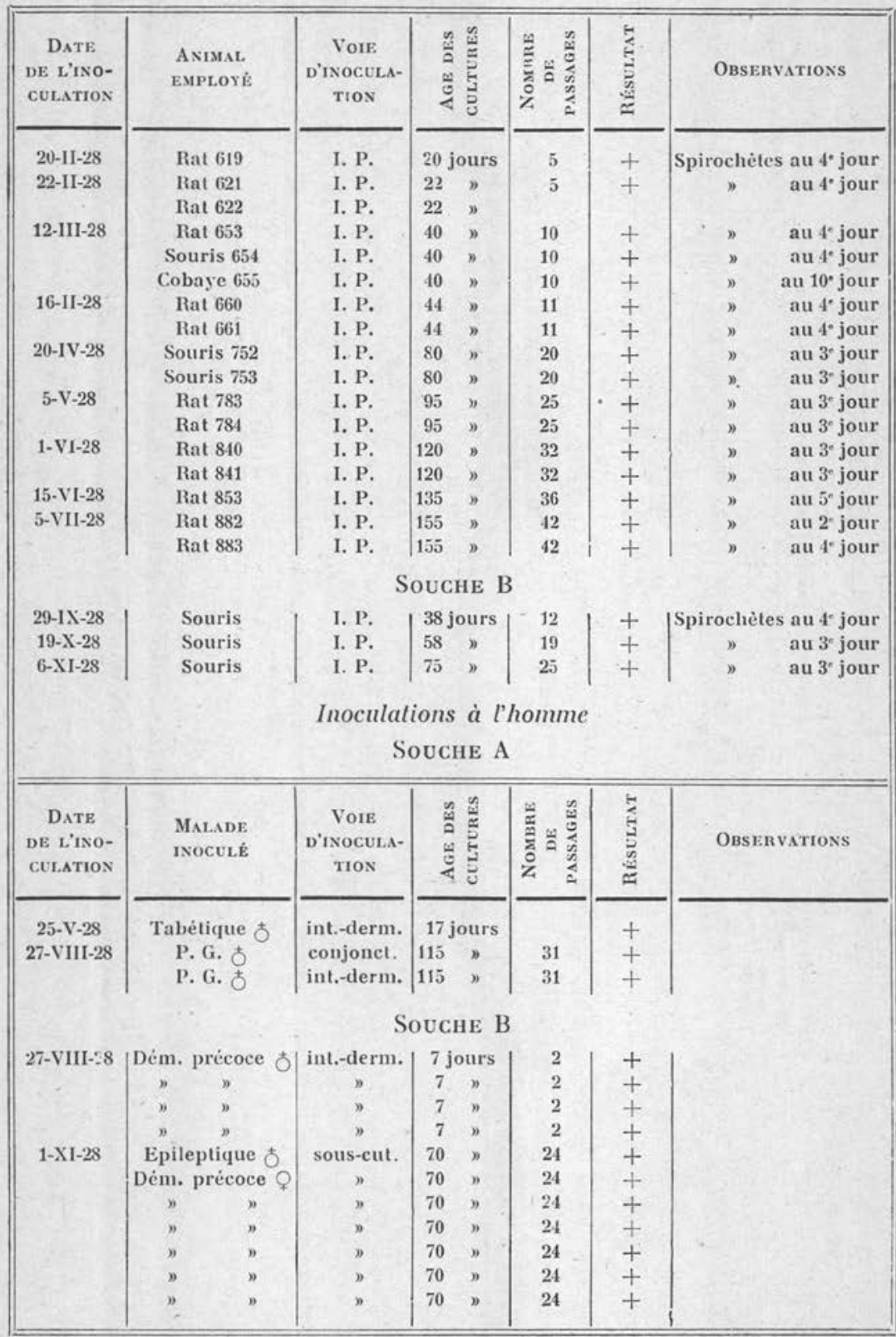


En résumé : les spirochètes de nos cultures se sont montrés constamment virulents pour les animaux et pour l'homme. On a pratiqué l'inoculation de 13 rats, 6 souris et un cobaye à différentes époques et toutes ont donné un résultat positif. D’autre part, on a inoculé 14 malades justiciables de la pyrétothérapie, tous également avec un résultat positif.

\section{RÉSUMÉ}

Dans ce travail nous exposons le résultat de recherches faites sur la culture du Treponema hispanicum Sadi de Buen, 1926. Nous avons réussi à cultiver facilement ce spirochète dans le milieu d'Ungermann simplifié (sérum pur de lapin non inactivé, non additionné de sang, en anaérobiose, à $37^{\circ}$ ). Nous avons conservé les spirochètes in vitro pendant 160 jours avec 43 passages. La virulence a été parfaitement conservée pour les animaux (20 animaux à différentes époques) et pour l'homme (14 inoculations).

\section{BibliogRaphiE}

Azsan (P.). - Algunas investigacienes clinicas y experimentales sobre la fiebre recurrente española. Archivos del Instituto Nacional de Higiene Alfonso XIII, V, 1926, p. 121-127.

Brumpt (E.). - Précis de Parasilologie, 4e édition, Par is, Masson, 1927.

- Les spirochètes. Nouveau Trailé de Médecine, Paris, Masson, IV, p. 535-578.

Lapidari (M.) et Sparrow (H.). - Sur la culture des spirochètes des fièvres récurrentes. Arch. Insl. Pasteur Tunis, XVII, 1928, p. 191-205.

Nicolle (Ch.) et Anderson (Ch.). - Etude comparative de quelques virus récurrents pathogènes pour l'homme. Arch. Insl. Pasteur Tunis, XVI, 1927, p. 123-206.

Seclion de Parasilologie de l'Instilul d'Hygiène de Montevideo 